\title{
The Sex Ratio and the Out-of-Wedlock Birth Rate in the United States during World War II
}

\author{
Robert E. McCormick ${ }^{1}$, Melissa M. Yeoh ${ }^{2} \&$ Mason S. Gerety $^{3}$ \\ ${ }^{1}$ John E. Walker Department of Economics, Clemson University, United States \\ ${ }^{2}$ Department of Economics, Campbell School of Business, Berry College, United States \\ ${ }^{3}$ W.A. Franke College of Business, Northern Arizona University, United States \\ Correspondence: Melissa M. Yeoh, Department of Economics, Campbell School of Business, Berry College, Mt. \\ Berry, Georgia 30149-5024, USA. Tel: 1-706-238-5893. E-mail: myeoh@berry.edu
}

Received: June 20, 2013 Accepted: July 18, 2013 Available online: August 24, 2013

doi:10.11114/ijsss.v1i2.155 URL: http://dx.doi.org/10.11114/ijsss.v1i2.155

\begin{abstract}
This paper provides a theoretical economic framework to study the effects of changes in the sex ratio on the out-of-wedlock birth rate in the United States. We model the demanders and suppliers of sexual relations as potential mates and the relative "price" of human sexual relations as the promises implicit within a traditional marriage (marriage, fidelity, wealth transfers, child support, etc.). We examine an instrument for the implicit "price" of sexual relations, namely the out-of-wedlock birth rate. We show that the reduction in the number of available sex partners for women during World War II decreased the "price"-in terms of marriage - that remaining men had to pay for sex. One result of this lower "price" is an increase in the number of children born out-of-wedlock during the war. According to our regression results, a reduction in the sex ratio of 10 males per 100 females in the U.S. population during World War II increased the out-of wedlock birth rate by six to ten percent.
\end{abstract}

Keywords: sex ratio, out-of-wedlock births, marriage, fertility

\section{Introduction}

The basic tenet of price theory is that relative prices matter. We explore this economic tenet in non-market settings such as the demand and supply for human sexual relations and for marriage. In particular, we analyze the question of whether the change in the sex ratio due to the exodus of young white males to fight in World War II affected the non-monetary or implicit price of sexual relations. Since most sex acts are transacted in non-market settings without quid pro quo exchanges, we can only examine one of the outcomes of the transaction, namely out-of-wedlock births. We show that the reduction in the number of available sex partners for women during the war reduced the non-monetary or implicit price that remaining men had to pay for sex. One result of this lower price is an increase in the number of children born out of wedlock. ${ }^{1}$

According to Willis (1999, S33), "In 1960, marriage was a virtual precondition for childbearing. By 1997, out-of-wedlock births accounted for 26 percent of fertility among whites and 36 percent among blacks." Thus, during the period of our study, out-of-wedlock births among whites are quite rare. We motivate our study of white out-of-wedlock births with some observations from the literature on African American male scarcity.

The idea that the balance between the number of men and women in a society may be an important determinant of social mores and relationships is not new, especially when applied to African Americans (Norment, 1992). McAdoo (1981) reports that there are between 35 to 45 black men available for every 100 black women, that is single men who are employed, out of jail, and non drug users. She also claims that for wealthy black women, the ratio is even more lopsided, one per hundred. Aborampah $(1989,323)$ discusses the effect of this low sex ratio on black women where "the low sex ratio puts black women at a disadvantage in mate selection. As a result of the black male shortage, there is intense competition for the available few." Staples $(1978,65)$ argues, "to bargain effectively, the black woman must use the enticement of sex ... Given the abundance of women around, he [the black male] does not have to wait too long, and her alternatives are limited because of the shortage of 
men." Braithwaite (1981) claims that the limited number of black men causes black women to compete with one another to secure the attention of the scarce black male. Guttentag and Secord (1983) find empirical evidence to support the assertion that this competition for men will lead to more out-of-wedlock births. Using cross-sectional data from the National Center for Health Statistics, they find a strong negative correlation between the sex ratios for nonwhites and the proportion of nonwhite live births that were out-of-wedlock [-0.76 in 1960 and -0.75 in 1970]. They conclude that that sex ratios and out-of-wedlock births are strongly correlated.

While these assertions and discussions are illuminating, they do not provide the setting of a natural experiment. We examine how the radical and unexpected changes in the sex ratio of males to females impact the incidence of out-of-wedlock births. To accomplish this, we follow Abramitzky, Delavande, and Vasconcelos (2011), who studied the impact of the large male scarcity in France during World War I, but we examine the American World War II experience, and confine our discussion to whites. Abramitzky et al. $(2011,124)$ found that, "men were more likely and women less likely to marry; out-of-wedlock births increased." The next section will present a model that allows for the changes in the sex ratio to affect the patterns of out-of-wedlock births.

\section{An Economic Model of Sexual Relations}

We adopt a demand and supply framework to determine the implicit "price" and quantity of matches that occur. In this non-market setting, the implicit "price" is defined as some combination of marriage and fidelity promises, legal obligations from marriage, and wealth transfers-either pre- or post-marriage-from a male to a female, which are common during this time period.

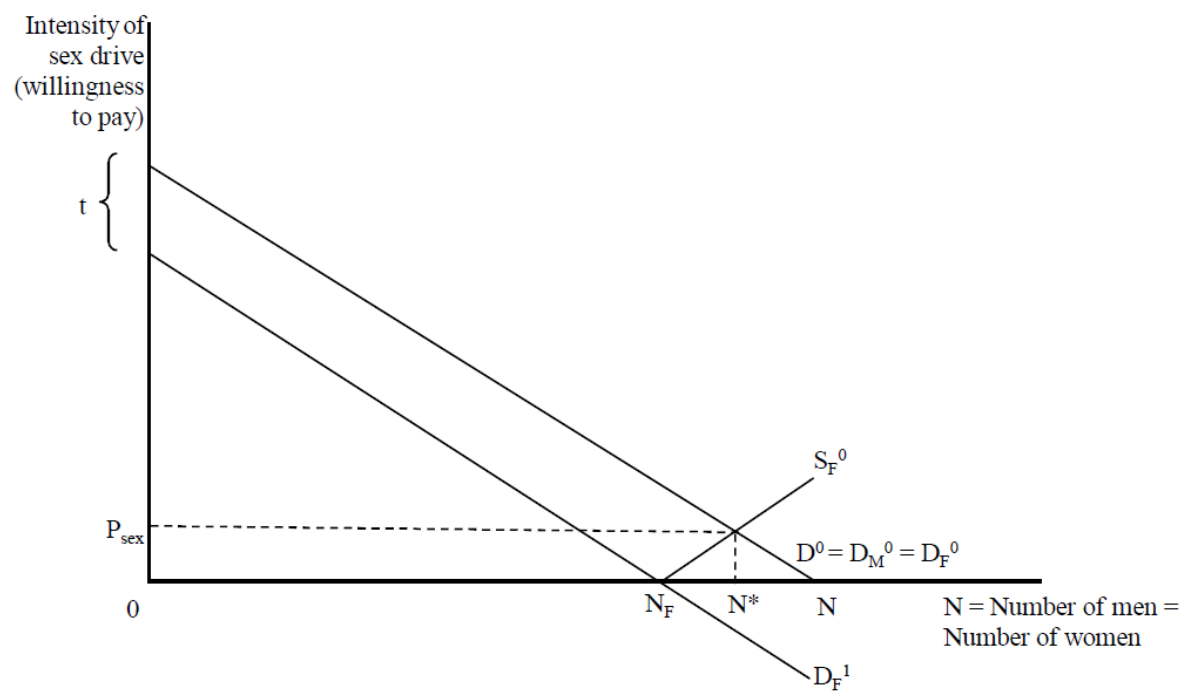

Figure 1. The Market for Sexual Relations between Heterosexual Males and Females Prior to World War II

In Figure 1, the $N$ number of males are arrayed according to the intensity of their demand for sex (or their willingness to "pay" the marriage "price" for sex) along the demand curve $D_{M}{ }^{0}$. The men are rank-ordered from left to right or from the highest demand intensity to the lowest demand intensity. Similarly, there are $N$ females in this population and they are also arrayed, from left to right, according to their intensity of demand or desire for sex along the demand curve $D_{F}{ }^{0}$. We assume that in a world where males and females are identical, except for their varying demand intensities for sex, the male demand curve $D_{M}{ }^{0}$ is exactly the same as the female demand curve $D_{F}{ }^{0}$ and every male and female would be matched. In fact, sexual matches occur at every point along the demand curve. Our assumption would result in $N$ matched couples in this world and no males or females remain unmatched.

We observe, however, that females bear an expected cost " $t$ " of possible pregnancy, which decreases their demand intensity for sex by the amount " $t$ ". The cost " $t$ " includes the health risk of bearing a child and the time and monetary expense involved in raising a child. Thus, the females' demand curve for sexual relations is shifted down by " $t$ " and results in the new curve $D_{F}{ }^{l}$. Note that $N-N_{F}$ women have a negative valuation for sexual relations. In fact, these women must be compensated in order to induce them to match with a man. The females who have smaller negative demand intensity for sex, are closer to the point $N_{F}$ and they require less compensation than females who have large negative demand intensity for sex (those who are closer to the point $N$ ). The $N$-th female in this population, the one with the lowest demand intensity for sex, would demand the entire amount " $t$ " as payment for matching with a male. The females who possess negative demand values for 
sex will match themselves to a male if he is willing to pay a "price"-like marriage, gifts, and monetary support-for them. These low sex drive females have become "suppliers" arrayed along the supply curve $S_{F}{ }^{0}$. This supply curve is obtained by pivoting the negative portion of the female demand curve, from $N_{F}$ to $D_{F}{ }^{l}$, to become $S_{F}{ }^{0}$. Both $S_{F}{ }^{0}$ and $D_{F}^{l}$ share the same horizontal intercept, $N_{F}$, and have the same slope (but with different signs, of course).

The equilibrium number of $N^{*}$ matches occurs where the new supply curve $S_{F}{ }^{0}$ intersects the male demand curve $D_{M}{ }^{0}$. The resulting implicit "price," $P_{\text {sex }}$, is the wealth transfer-which includes marriage obligations, gifts, and monetary support-demanded by all married women. Since a man cannot differentiate between high demand intensity women and low demand intensity women, he has to pay the price of $P_{\text {sex }}$ to the woman that he marries. Thus, the high demand intensity females are price-protected by the low demand intensity females. There are, however, $2\left(N-N^{*}\right)$ men and women who do not match with a spouse.

This framework is useful to analyze our question of relative price because a decrease in the effective sex ratio can be modeled as a downward shift in the men's demand curve, shown in Figure 2. The exodus of men to fight in World War II shifted the males' demand curve for sex from $D_{M}{ }^{0}$ to $D_{M}{ }^{l}$. Due to the relative scarcity of men, the remaining males pay a lower price, new $P_{s e x}$, to their spouses. Also note that there are fewer couples, $N^{* *}$, who are matched after the exodus of soldiers sent to fight abroad.

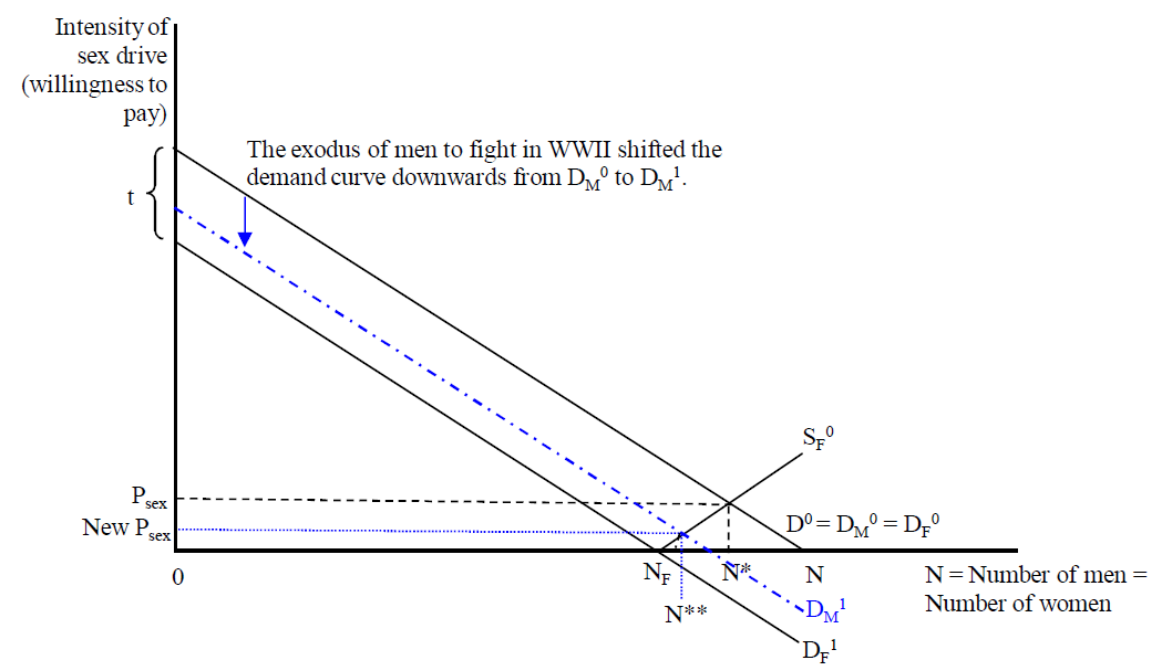

Figure 2. The Market for Sexual Relations between Heterosexual Males and Females during World War II

The new $P_{\text {sex }}$ could be interpreted as a smaller wealth transfer that is obtained by the married females or the lack of a marriage bond prior to sexual relations. Females, who previously could expect a legal marriage contract from a man before engaging in sex, now have to accept a lower "price" for sexual relations. The relative scarcity of men induce women into competition for the remaining available men, including sexual competition where women would have sex with men without the benefit of marriage and without the use of birth control, thus resulting in out-of-wedlock births. This situation describes an equilibrium where the increased level of out-of-wedlock births is determined by the decrease in the sex ratio. The next section describes our data sources and provides some econometric evidence for the predictions of the model.

\section{The Data and Some Evidence}

In this section, we collect census data to directly test the prediction of our model regarding the effect of the change in the sex ratio on the out-of-wedlock birth rate. In order to compute the sex ratio during the war, we start with the number of males and the number of females in each state as counted by the 1940 census. Then, we subtract from the male population in each month, the number of draftees called by the Selective Service, starting in December 1940. We then recomputed the sex ratio using the revised number of males relative to the number of females. At the end of the war, the surviving males return. Table 1 shows the sex ratio for the United States (averaged for 42 states in our data set) for the period 1940-1945, except 1942 for which data are not available. The highest sex ratio of men to women over this period occurs in Nevada in 1941 and the lowest sex ratio is found in the District of Columbia in 1945. The national sex ratio decreased dramatically throughout the war period, resulting in the lowest sex ratio in 1945 where there were only 80.9 males per 100 females in the country. 
Table 1. U.S. average male-female population ratio for 42 states

\begin{tabular}{ll}
\hline Year & Male-Female Ratio (Computed) \\
\hline 1940 & 0.95 \\
1941 & 0.895 \\
1943 & 0.848 \\
1944 & 0.824 \\
1945 & 0.809 \\
\hline
\end{tabular}

Source: U.S. Census Bureau

As predicted by our model, the decrease in the sex ratio is accompanied by a sharp increase in the out-of-wedlock birth rate from 1943 to 1945, as depicted in Figure 3. We are unable to obtain data for 1942. The downward trend present prior to the war reverses itself during the war and appears to return to long-run trend levels after the war. The U.S. average out-of-wedlock birth rate (for whites) over the war period is 19.3 per 1000 live births. The lowest incidence is found in Utah in 1943 at 6.1 and the highest is observed in Maine in 1945 at 50.5.

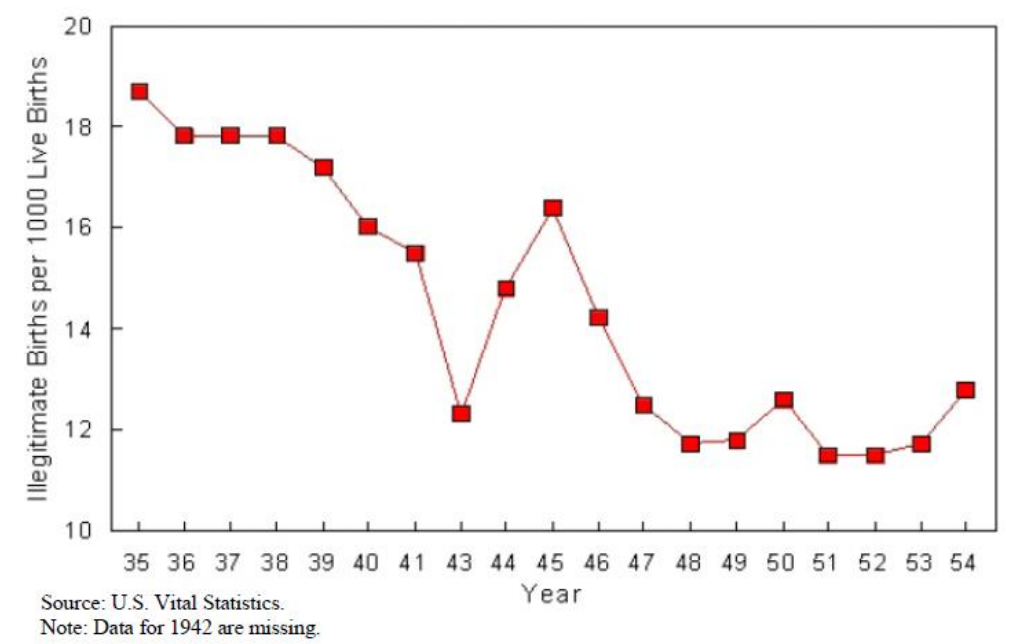

Figure 3. U.S. average out-of-wedlock births per 1000 live births (whites only)

We also present some econometric evidence for the relationship between the sex ratio and the out-of-wedlock birth rate. The summary statistics of the data are presented in Table 2. Recall that we have data on 156 state-year observations that spans 1941-1945 (except 1942) and includes 42 states. ${ }^{2}$ The dependent variable of interest is each state's out-of-wedlock births per 1000 live births. We include the out-of-wedlock birth rate in 1935 as a baseline control variable. We also control for each state's income per capita, median years of school, population density, four-firm church concentration ratio and church membership in 1950. The independent variable of interest is the sex ratio or the male to female ratio, either contemporaneous with the out-of-wedlock births data or lagged by one year. We lag the sex ratio by one year because any change in the price of sexual relations (especially out-of-wedlock sex) will only manifest itself after a nine-month gestation period.

Table 2. Summary Statistics for 42 States during 1941-1945 (Except 1942)

\begin{tabular}{llllll}
\hline Variable & Obs & Mean & Std. Dev. & Min & Max \\
\hline Out-of-wedlock Birth Rate in 1935 & 156 & 19.89 & 6.67 & 8.53 & 41.42 \\
Out-of-wedlock Births per 1000 Live Births & 156 & 19.29 & 8.15 & 6.10 & 50.50 \\
Income per Capita & 156 & 540.23 & 187.10 & 242 & 1066 \\
Median Years of Schooling & 156 & 8.91 & 0.82 & 7.8 & 12.1 \\
Population Density & 156 & 194.97 & 749.76 & 0.94 & 4743.26 \\
Military Draftees & 156 & 30540.25 & 42041.11 & 1050 & 340012 \\
Male/Female Ratio (contemporaneous) & 156 & 0.93 & 0.08 & 0.76 & 1.24 \\
Male/Female Ratio (lagged one year) & 156 & 0.95 & 0.08 & 0.77 & 1.26 \\
4-Firm Church Concentration Ratio & 156 & 75.60 & 10.13 & 51.70 & 96.60 \\
Church Membership in 1950 & 156 & 47.02 & 11.37 & 27.70 & 75.70 \\
Percent Protestant in 1950 & 156 & 30.13 & 10.09 & 13.80 & 68.80 \\
Percent Catholic in 1950 & 156 & 15.52 & 12.79 & 0.60 & 58.90 \\
Percent Jewish in 1950 & 156 & 1.21 & 1.57 & 0 & 7.50 \\
\hline
\end{tabular}

Source: U.S. Census Bureau and U.S. Vital Statistics 
We use ordinary least squares (OLS) to estimate the following out-of-wedlock births regression equation:

Out-of-wedlock births $\mathrm{j}_{\mathrm{jt}}=\beta_{0}+\beta_{1}$ (out-of-wedlock births in 1935) $)_{\mathrm{j}}+\beta_{2}$ (median years of schooling) ${ }_{\mathrm{j}}+\beta_{3}$ (income per capita) $)_{\mathrm{j}}+\beta_{4}$ (population density $)_{\mathrm{j}}+\beta_{5}$ (male-female ratio $)_{\mathrm{jt}}+\beta_{6}$ (4-firm church concentration ratio $)_{\mathrm{j}}+\beta_{7}$ (church membership in 1950 $)_{\mathrm{j}}+\beta_{8}(\text { year dummies })_{\mathrm{t}}+\beta_{9}$ (state dummies $)_{\mathrm{j}}+\varepsilon_{\mathrm{jt}}$

for $\mathrm{j}=42$ states and $\mathrm{t}=1941,1943,1944$, and 1945. Note that we use two different measures of the male-female ratio: contemporaneous and lagged by one year.

Table 3. OLS Regressions for 42 States during 1941-1945 (except 1942)
(1)
(2)
(3)
(4)

Dependent variable: Out-of-wedlock births per 1000 live births

\begin{tabular}{lllll}
\hline Male/female ratio (contemporaneous) & $-12.813^{* *}$ & & $-18.306^{* *}$ & \\
Male/female ratio (lagged one year) & {$[4.713]$} & & {$[5.402]$} & \\
& & $-19.587^{* *}$ & & $-29.876^{* *}$ \\
& & {$[5.057]$} & & {$[5.520]$} \\
Out-of-wedlock birth rate in 1935 & $1.109^{* *}$ & $1.104^{* *}$ & $1.175^{* *}$ & $1.178^{* *}$ \\
& {$[0.074]$} & {$[0.071]$} & {$[0.096]$} & {$[0.084]$} \\
Median years of schooling & $1.955^{*}$ & $2.198^{* *}$ & $3.043^{* *}$ & $3.636^{* *}$ \\
& {$[0.805]$} & {$[0.782]$} & {$[1.098]$} & {$[0.963]$} \\
Income per capita & $-0.008^{* *}$ & $-0.007^{* *}$ & -0.001 & 0.003 \\
& {$[0.002]$} & {$[0.002]$} & {$[0.005]$} & {$[0.004]$} \\
Population density & 0.0006 & 0.0003 & -0.0014 & $-0.0024^{*}$ \\
& {$[0.0009]$} & {$[0.0009]$} & {$[0.0011]$} & {$[0.0010]$} \\
4-Firm church concentration ratio & $-0.132^{* *}$ & $-0.137^{* *}$ & $-0.151^{* *}$ & $-0.141^{* *}$ \\
& {$[0.038]$} & {$[0.037]$} & {$[0.054]$} & {$[0.048]$} \\
Church membership in 1950 & $0.072^{*}$ & $0.07^{*}$ & -0.021 & -0.076 \\
& {$[0.031]$} & {$[0.032]$} & {$[0.046]$} & {$[0.041]$} \\
Constant & 2.199 & 7.498 & -0.349 & 6.226 \\
& {$[7.507]$} & {$[7.359]$} & {$[9.519]$} & {$[8.070]$} \\
State fixed effects? & No & No & Yes & Yes \\
Observations & 156 & 156 & 156 & 156 \\
R-squared & 0.78 & 0.8 & 0.86 & 0.88 \\
Robust standard errors in brackets & & & & \\
* significant at 5\%; ** significant at $1 \%$ & & & & \\
\hline
\end{tabular}

The out-of-wedlock births regression results are presented in Table 3. In columns (1) and (2) the independent variable of interest, the lagged and contemporaneous male-female ratio, is negative and statistically significant in explaining out-of-wedlock birth rates during the war. A 10 percent decrease in the sex ratio (a reduction of 10 males per 100 females in the population) in a given year will result in an increase of 1.96 out-of-wedlock births per 1000 live births in the following year. While a 10 percent decrease in the contemporaneous sex ratio will result in an increase of 1.28 out-of-wedlock births per 1000 live births. These are significant effects considering that the average out-of-wedlock birth rate during 1941-45 is 19.29 births per 1000 live births. A change of 1.28 to 1.96 births per 1000 live births results in a six [(1.28/19.29)*100\%] to ten percent [(1.96/19.29)*100\%] change in the out-of-wedlock birth rate. These results are certainly plausible because during World War II, the average male-female population ratio decreased from 0.95 in 1940 to 0.809 in 1945, a reduction of almost 14 men per 100 women (see Table 1).

We add state dummy variables in columns (3) and (4) to control for unobservable state-specific effects that could influence the out-of-wedlock birth rate in each state. We obtain larger positive and statistically significant coefficients for the contemporaneous and lagged sex ratio variables, indicating that the variation in the sex ratio is an important explanatory variable for the changes in the out-of-wedlock birth rate during this period.

In all four specifications in Table 3, the baseline out-of-wedlock birth rate in 1935 is positive and statistically significant in explaining the out-of-wedlock birth rate during the war years. These positive coefficients show that the out-of-wedlock birth rate during World War II was about 1.1 births more per 1000 live births compared to 1935. The coefficient for median years of schooling is positive and statistically significant, suggesting that states with better educated populations have higher out-of-wedlock birth rates during the war. The median level of education in a state may be correlated with the levels of tolerance within a state. For instance, states with higher 
median years of schooling tend to be in the West and Northeast (liberal states), while states with lower median years of schooling tend to be in the South (conservative states where the social censure for out-of-wedlock births is more severe). ${ }^{3}$ Higher income states tend to have lower incidences of out-of-wedlock births during the war. Population density, however, does not significantly affect the out-of-wedlock birth rate in the states. The four-firm church concentration ratio, which measures the total market share (in terms of adherents) of the four largest religious institutions in each state, is negative and significant in explaining out-of-wedlock birth rates during the war. States with a high religious concentration ratio (such as Utah, with $96.6 \%$ of the population belonging to the four largest religious establishments within the state) may have a lower tolerance for out-of-wedlock births.

The results in Table 3 suggest that the sharp decrease in the male-female population ratio increased the bargaining power of males relative to females. Thus, the remaining males do not have to pay as high a "price" to couple with females during the war and the decrease in the "price" of sexual relations resulted in increased out-of-wedlock births.

\section{Alternative Explanations}

The argument may be made that the observed increase in the out-of-wedlock birth rate is due to alternative phenomena. In this section we address the possibility of what we call the time horizon problem. One dimension in which people pay for behavior is the opportunity cost of time. When one's expected time horizon is short, costly behavior becomes relatively less expensive. An extreme example is that of war. Just as Vietnam era veterans consumed more heroin during their tour of duty than they did before or after their service (Robins, Davis and Goodwin, 1974), so too may be the case among wartime women consuming more out-of-wedlock sex, with its accompanying consequences. The social stigma of the out-of-wedlock child is conceivably less severe during war. The whispers of the neighbors pale in comparison to the wrath of the Blitzkrieg. We therefore have an alternative hypothesis with testable implications.

If there indeed existed genuine fear as to the future of the United States, then under the time horizon hypothesis we would expect various other time-dependant series to be affected. Foremost, in the case of world war, one would expect observed interest rates to reflect a sudden shift in time preferences. Moreover, one cannot imagine a steeper yield curve than one in which both the issuer and holders of long-term debt may not exist in the near future (Aase, 2009). We therefore obtained data on short-term and long-term rates during the WWII period. Unfortunately, interest rates were controlled by the federal government during most of this period. For example, from the middle of 1943 through 1947, the rate on three-month T-bills was pegged at 0.375 percent. Indeed most other rates were virtually constant during this period. Thus we see no real chance to test this time horizon theory.

In a second attempt, we looked at life insurance policies. Again, the same reasoning applies. A casual interpretation of the data shows a steady increase in the number of policies in force and coverage per family when in fact the theory predicts a decline. When your world may be coming to an end, there is little reason to pay for a policy that none of your loved ones can collect on. What is especially interesting about these data are that they relate only to what is referred to as legal reserve life insurance companies. These are companies operating under insurance laws specifying the minimum basis for the reserves a company must maintain on its policies. Veterans life insurance policies issued by the federal government to members of the Armed Forces during this period are not included. Therefore the rise in policies cannot be attributed to the millions of military personnel at high risk of dying. We suggest a possible interpretation of these data is that indeed the time horizon problem was not substantial (Hakansson, 1969). In fact, the simultaneous rise in the number of policies and fall in the average size of policies, we suggest, may be a result of more, not fewer, less wealthy (relative to men) women purchasing policies. Thus this interpretation is not consistent with the time horizon problem theory.

\section{Conclusion}

In our economic model of sexual relations, men are net demanders of sexual activity. While both men and women enjoy the physical act of sexual relations, women bear a larger expected cost of child bearing and child rearing and are therefore, net suppliers of sexual activity. Women negotiate for the supply of sex via a marriage commitment from men to assist in the rearing of any child that might ensue from a random sex act. Women shift part of the cost of pregnancy and child rearing to men by requiring a long-term marriage commitment in order to supply their portion of the sex act. Competition between women for a shrinking number of men erases the ability of many women to sustain the demand for marriage commitments. The result is an increasing number of sex acts outside the bounds of marriage. When the number of men relative to the number of women decreases, the implicit "prices" tilt in favor of men, and they are less regularly required to make the long-term commitment of marriage in order to enjoy regular sexual relations. When females are plentiful, competition between women 
reduces the request on their part that the man make a long-term commitment. According to our regression results, a reduction in the sex ratio of 10 males per 100 females in the U.S. population during World War II increased the out-of wedlock birth rate by six to ten percent. To recapitulate, we find some evidence that the sex ratio affects the implicit "price" of sexual relations, namely the number of out-of-wedlock births.

\section{Acknowledgement}

We thank Eric Bertonazzi and Jody Lipford for their help in earlier drafts of this paper. All remaining errors are ours.

\section{References}

Aase, K. K. (2009). “The Investment Horizon Problem: A Resolution.” NHH Department of Finance and Management Science Discussion Paper No. 2009/7. http://dx.doi.org/10.2139/ssrn.1496846

Abramitzky, R., Delavande, A., \& Vasoncelos, L. (2011). "Marrying Up: The Role of Sex Ratio in Assortative Matching." American Economic Journal: Applied Economics, 3, 124-157. http://dx.doi.org/10.1257/app.3.3.124

Aborampah, O. M. (1989). Black Male-Female Relationships: Some Observations. Journal of Black Studies, 19(3), 320-342. http://www.jstor.org/stable/2784662

Braithwaite, R. L. (1981). Interpersonal Relations between Black Males and Black Females, pp. 83-97 in L. E. Gary (ed.) Black Men. Beverly Hills, CA: Sage Publications.

Guttentag, M., \& Secord, P. F. (1983) Too Many Women? The Sex Ratio Question. Beverly Hills, CA: Sage Publications.

Hakansson, N. H. (1969). Optimal Investment and Consumption Strategies under Risk, an Uncertain Lifetime, and Insurance. International Economic Review, 19(3), 443-466. http://www.jstor.org/stable/2525655

McAdoo, H. P. ed. (1981). Black Families. Beverly Hills, CA: Sage Publications.

Norment, L. (1992). Guess Who's Coming to Dinner Now? Ebony, September.

Posner, R. A. (1994) Sex and Reason. Cambridge, MA: Harvard University Press.

Robins, L. N., D. H. Davis, \& Goodwin, D. W. (1974). Drug Use by U.S. Army Enlisted Men in Vietnam: A Follow-Up on Their Return Home. American Journal of Epidemiology, 99, 235-249. http://aje.oxfordjournals.org/content/99/4/235

Staples, R. (1978). The Black Dating Game," in R. Staples (ed.) The Black Family Essays and Studies. Belmont, CA: Wadsworth.

Willis, R. J. (1999). A Theory of Out-of-Wedlock Childbearing. Journal of Political Economy, 107(6), S33-64. http://dx.doi.org/10.1086/250103

\section{Notes}

Note 1. Posner $(1994,136)$ defines the effective sex ratio as "the ratio of males to available females." High effective sex ratios lead to more homosexual contacts and the use of prostitutes. Low effective sex ratios lead to an increase in out-of-wedlock births. Posner focuses on urban black America for his supporting evidence, and claims that because the effective sex ratio for urban blacks is so low, "that with so favorable an effective sex ratio, black men (outside of prison) will be less likely than white men to engage in opportunistic homosexual behavior or patronize prostitutes but are more likely to have multiple sex partners, to be initiated into sex early, and to father illegitimate children." (p. 138).

Note 2. We only have one year's observation for Colorado, Connecticut, and New Mexico and 3 years' observations for Arizona, Idaho, and Nevada. The nine states not included in our data set are Alaska, California, Hawaii, Maryland, Massachusetts, Nebraska, New Hampshire, New York, and Wyoming.

Note 3. The top ten states with the highest median years of schooling are the District of Columbia, Utah, Nevada, Washington, Oregon, Maine, Arizona, Florida, Colorado, and Texas. The bottom ten states with the lowest median years of schooling are Kentucky, West Virginia, Tennessee, Arkansas, North Carolina, Alabama, Louisiana, New Mexico, Virginia, and Georgia.

\section{(cc) $\mathrm{Br}$}

This work is licensed under a Creative Commons Attribution 3.0 License. 